\title{
LA EDUCACIÓN ESTÉTICO-AMBIENTAL (EEA) ANTE EL IMPACTO ANTIESTÉTICO DE LA CRISIS SOCIOAMBIENTAL
}

\author{
Pablo René Estévez Rodríguez ${ }^{1}$, Lurima Estevez Alvarez ${ }^{2}$ y Elisabeth Brandão Schmidt ${ }^{3}$
}

\author{
[...] el capital es en realidad \\ la causa eficiente de la desestabilización \\ de los ecosistemas (...) \\ Por doquiera que pasa, \\ debido a la intromisión \\ de la forma mercantil, \\ se rompen los principios ecológicos \\ que sustentan el surgimiento \\ y florecimiento de la vida, \\ la belleza y la conciencia. \\ Joel Kovel
}

\section{RESUMEN}

El artículo centra la atención en el impacto antiestético de la crisis socioambiental contemporánea sobre los seres humanos debido al cambio climático, la polución ambiental y otros, destacando el papel de la Educación Estético-Ambiental (en especial, de los procedimientos de sensibilización) para la preservación y/o rescate de la condición humana. En particular, se alude a las representaciones de académicos (as) de Artes Visuales - Licenciatura de la Universidad Federal de Rio Grande - FURG (Brasil) y de instructores (as) de Arte de Manicaragua (Cuba) sobre la EEA y su papel en una formación más integral de la personalidad. Dicho estudio (eminentemente cualitativo) se fundamenta en la perspectiva hermenéutico-dialéctica de Minayo y demuestra la pertinencia de las experiencias transculturales para fomentar esta modalidad educativa.

Palabras-Clave: Educación Ambiental; Educación Estético-Ambiental; Crisis socioambiental; Impacto antiestético.

\section{RESUMO}

O artigo focalizou a atenção no impacto antiestético da crise socioambiental contemporânea sobre os seres humanos, devido à mudança climática, à poluição ambiental entre outros, destacando o papel da Educação Estético-Ambiental (em especial dos procedimentos de sensibilização) para a preservação e/ou resgate da condição humana. Apresenta as representações de acadêmicos (as) em Artes Visuais Licenciatura da Universidade Federal do Rio Grande - FURG (Brasil) e de instructores (as) de Arte de Manicaragua (Cuba) sobre a EEA e seu papel na formação integral da personalidade. O estudo

\footnotetext{
${ }^{1}$ Doctor en Ciencias Filosóficas. Profesor Titular. Investigador Auxiliar. Consultor Científico de la Asociación de Pedagogos de Cuba. Colaborador del Departamento de Educación Artística del Ministerio de Educación de Cuba y miembro de la Comisión Nacional de Planes y Programas del I Instituto Central de Ciencias Pedagógicas. E-mail: pablorene@cenit.cult.cu; esteticaeducacion@gmail.com

${ }^{2}$ Doctora en Educación Ambiental. Profesora Asistente. Investigadora Auxiliar. Miembro de la Asociación de Pedagogos de Cuba. E-mail: lurimaestevezalvarez@ gmail.com

${ }^{3}$ Doctora en Educación. Profesora Titular del Programa de Pós-Graduação em Educação Ambiental y del Programa de Pós-Graduação em Educação de la Universidade Federal do Rio Grande (FURG), Rio Grande, Rio Grande do Sul, Brasil. E-mail: elisabethschmidt@furg.br
} 
(eminentemente qualitativo) é baseado na perspectiva hermenêutica-dialética de Minayo e demonstra a pertinência das experiências transculturais para fomentar esta modalidade educativa.

Palavras-Chave: Educação Ambiental; Educação Estético-Ambiental; Crise socioambiental; Impacto antiestético.

\section{ABSTRACT}

The article focused on the unsightly impact of the contemporary socio-environmental crisis on humans due to climate change, environmental pollution and others, highlighting the role of Aesthetic-Environmental Education (in particular, awarenessraising procedures) for the preservation and/or rescue of the human condition. In particular, it was alluded to the representations of Visual Arts students at the Universidade Federal do Rio Grande - FURG (Brazil) and Arts instructors from Manicaragua (Cuba) on the EEA and its role for a more comprehensive education of the personality. The study (eminently qualitative) was based on Minayo's hermeneuticdialectical perspective and demonstrated the relevance of transcultural experiences to promote this educational modality.

Keywords: Environmental Education; Aesthetic-Environmental Education; Socioenvironmental crisis; Unsightly impact.

\section{INTRODUCCIÓN}

Son harto conocidas las consecuencias de la crisis socioambiental global que aqueja al mundo de hoy. Algunos sorprendentes indicadores (con un innegable impacto antiestético) fueron sintetizados por Yann Arthus-Bertrand en el documental Home, retomados por Fidel Castro en una de sus reflexiones en el Diario Granma y referenciados por Estévez en el acápite "La sustentabilidad estética en el desarrollo humano", del libro A Educação Ambiental em perspectiva estética (2011: p.22-23).

Tras una revisión rápida a nuestro fichero personal sobre dicho impacto, pudimos cerciorarnos, una vez más, de la importancia de asumir la sustentabilidad estética como un principio fundamental del desarrollo humano y social. En particular, de la propia Educación Ambiental: muchas veces circunscrita a meras terapias de choque en las comunidades, donde se obvia la necesidad del cambio de mentalidades (como sugirió BOKOVA, 2015: p.5), a fin de enfrentar las consecuencias del cambio climático. Es por ello que este texto constituye un modo de posicionarnos frente a problemáticas socioambientales que están pautando la vida de las personas y, en sentido general, degenerando la condición humana. Y ante este hecho, se torna urgente la implementación de la Educación Estético-Ambiental, como modalidad estético- 
educativa que, sustentada en los dominios de lo estético y de lo ambiental, pretende fomentar y fortalecer la educación en valores.

\section{La crisis socio-ambiental}

Basta enumerar algunas de las reales y potenciales pérdidas, con una elevada significación estética, para percatarnos de la magnitud de la amenaza anestésica:

a) En virtud de la desertificación (por la tala de árboles, destrucción de la vegetación herbácea y la erosión provocada por la acción de la lluvia y el viento), laderas y valles del Líbano, Siria, el litoral de Egipto y Túnez se han transformado en verdaderos desiertos o semidesiertos.

b) [...] una parte considerable del desierto de Sonora, en Arizona, y la casi totalidad del existente en Nuevo México, deben su presencia al pastoreo excesivo practicado en el transcurso de siglos, al igual que las vastas extensiones de tierras áridas del Asia Central [...] Estos desiertos han proseguido avanzando por todo el planeta y en la actualidad representan una seria amenaza al desarrollo sostenible de la humanidad entera [...]. (PELÁEZ, 2016, p. 8)

c) Las expectativas que crea el cambio climático para los pequeños estados insulares, "incluidas las Islas Cook, Tuvalu y Nauru", son verdaderamente apocalípticas: sobre todo, en virtud de la falta de consenso entre los países más industrializados (en especial, el Grupo de los Ocho) para enfrentar sus consecuencias. (RICHARDS, 2012, p. 8)

d) Los biocombustibles se "roban" la comida, especialmente en México y otros países donde el maíz constituye una parte esencial de la dieta, agravando la crisis alimentaria que padece la humanidad. En México, en particular, el precio de la tradicional tortilla de maíz se elevó un $60 \%$ desde el 2005, según indicaron Timothy Wise, director del Programa de Investigación y Política del Instituto de Desarrollo Global y Medio Ambiente de la Universidad de Tufts, y Marie Brill, directora de políticas de Action Aid Internacional, en una investigación realizada al efecto. (GODOY, 2012, p. 8)

e) Se acrecienta la producción de residuos, especialmente de componentes electrónicos, en virtud de la obsolescencia programada (la obsolescencia técnica; la obsolescencia de calidad y la obsolescencia por modas, deseabilidad o psicológica) que asume la industria capitalista como estrategia para preservar sus intereses mercantiles. Esto, a su vez, a través de la denominada "ayuda para el desarrollo", contribuye a la diseminación de cementerios de residuos, principalmente, en países de África y Asia. ${ }^{4}$

\footnotetext{
${ }^{4}$ Ver HERnÁndeZ REY, L. Tecnología con los días contados. Periódico Granma, La Habana, Año $52, \mathrm{n}^{0} .30$, p. 7, febrero 2016.
} 
Algunas reseñas tomadas al azar de la Sección Hilo Directo del Periódico Granma $^{5}$, correspondientes a los primeros días de agosto de 2017, cuando redactábamos este ensayo, demostraron la banalización de las problemáticas relacionadas con el cambio climático y de las predicciones catastróficas de sus consecuencias potenciales para la vida en el planeta. He aquí solo algunos ejemplos:

- El calentamiento de la Tierra será mayor de dos grados centígrados en el presente siglo, con probabilidades de llegar hasta 4,9 en una centuria [...] solo existe un $5 \%$ de probabilidad de que la Tierra se caliente por debajo de los dos grados, y solo el $1 \%$ de que se reduzca la temperatura en 1,5 grados centígrados, tal como lo estipula el Acuerdo de París del 2015. (02/08/2017, p.6)

- La calidad del aire en el planeta empeorará paulatinamente, lo cual puede causar 60000 muertos anuales para el 2030 por afecciones de salud derivadas de la contaminación atmosférica [...] con el progreso del calentamiento global, algunos efectos del cambio climático conducirán a una mayor permanencia de sustancias contaminantes en el aire. (03/08/2017, p.4)

- Debido al calentamiento global, para el 2100 las temperaturas extremas podrían volver inhabitable el sur de Asia, donde vive la quinta parte de la población global. Las regiones más afectadas serían posiblemente el norte de India, Bangladés y el sur de Pakistán, lugares donde residen un total de 1500 000000 personas [...] Este escenario será inevitable si no se toman medidas para reducir los gases de efecto invernadero. (04/08/2017, p.6)

- [...] La caza furtiva, la destrucción de nidos y del hábitat en general, junto a cambios en los patrones de reproducción provocados por el cambio climático, son algunos de los factores que intervienen en la progresiva desaparición de estas especies [las tortugas marinas, acréscimo de los autores] ya en peligro de extinción. (07/08/2017, p.4)

En fin, son muchos los ejemplos que pudieran acotarse, donde se pone de manifiesto la gravedad de la crisis socioambiental que azota al mundo, como pandemia de la irracionalidad que Max Horkheimer denominó enfermedad de la razón: una enfermedad que parece incurable, como demuestra un informe del National Intelligence Council (NIC), la oficina de análisis y de anticipación geopolítica y económica de la Central Intelligence Agency (CIA), tal como dio a conocer Ramonet en el artículo intitulado "El mundo en el 2030" (2013, p. 1-3), publicado en el Periódico Le Monde Diplomatique. ${ }^{6}$

\footnotetext{
${ }^{5}$ Periódico cubano fundado en 1965. Órgano del Comité Central del PCC.

${ }^{6}$ Dicho informe prevé la emergencia de conflictos por áreas de influencias en el comercio, crimen organizado, guerras electrónicas y agotamiento de recursos naturales, como el agua. "En el 2030, el 60\%
} 
A lo anterior se suma la carrera armamentista que, como bien la bautizó Fidel, representa un peligroso paso hacia el abismo. Según él,

[...] Es bien conocido que el gobierno de Estados Unidos se opuso a los acuerdos de Kyoto sobre el medio ambiente, una línea de conducta que ni siquiera concibió con sus más cercanos aliados, cuyos territorios sufrirán tremendamente y algunos de los cuales, como Holanda, desaparecerían casi por entero.

El planeta marcha hoy sin política sobre este grave problema, mientras los niveles del mar se elevan, las enormes capas de hielo que cubren la Antártida y Groenlandia, donde se acumula más del $90 \%$ del agua dulce del mundo, se derriten con creciente ritmo, y ya la humanidad, el pasado 30 de noviembre de 2011, alcanzó oficialmente la cifra de 7 mil millones de habitantes que en las áreas más pobres del mundo crece de forma sostenida e inevitable. ¿Es que acaso los que se han dedicado a bombardear países y matar millones de personas durante los últimos 50 años se pueden preocupar por el destino de los demás pueblos?

Estados Unidos es hoy no solo el promotor de esas guerras, sino también el mayor productor y exportador de armas del mundo. (CASTRO, 2012)

El rechazo de Donald Trump a ratificar los acuerdos que, respecto al cambio climático, fueron alcanzados en la Conferencia de París (2015), representó un duro golpe a las esperanzas de miles de millones de seres humanos que aspiran a un modo de vida sustentable, que sea capaz de preservar la vida inteligente en el planeta Tierra: algo que hasta ahora no parece concebible

\section{El impacto antiestético de la crisis socio-ambiental}

Es un hecho que una de las dimensiones del proceso de globalización en la sociedad contemporánea lo constituye la globalización de la fealdad: mayormente, como resultado de la crisis socioambiental. La fealdad aflora como un mal endémico necesario en virtud de los desequilibrios de los ecosistemas por causas ecológicas y/o sociales. Entre ellas:

de la población mundial tendrá problemas de abastecimiento de agua, dando lugar a la aparición de conflictos hídricos", según se afirmó en el documento.

${ }^{7}$ Para ilustrar la última afirmación de Fidel basta enumerar los "diez grandes de la industria de la guerra": Lockhee Martin, Boeing, BAE System, Raytheon, General Dynamics Corp., Northrop Grumman, United Technologies, Finmeccanica y L-3 Communicatione Holdings Inc., responsables por la producción de aviones, misiles, radares, barcos, vehículos de combate y super bombas como la MOP. Diseñada para destruir instalaciones nucleares subterráneas, especialmente, en Irán y Corea del Norte (Los diez grandes de la industria de la muerte, 2016, p.6). 
a) La pérdida de la biodiversidad estética por la desaparición de innumerables paradigmas estéticos. Esto es: entes de la flora, la fauna y otros con una correlación única entre su contenido y su forma.

Una causa fundamental de esta merma reside en la proliferación de agronegocios de emporios internacionales que, como Monsanto, manipulan los códigos genéticos de las semillas, con la finalidad de aumentar la productividad de las cosechas; plantan grandes bosques de pinos y/o pastizales para la industria papelera, la producción de etanol o carne bovina para los mercados de Estados Unidos, Japón y Europa. Como resultado, se acrecienta la escasez de alimentos y la expectativa de hambrunas de una población que crece en una proporción geométrica.

b) El cambio climático por su impacto sobre la biodiversidad; la pérdida de paisajes naturales y urbanos, incluyendo la posible desaparición de islas y países, y de especies tan estéticamente paradigmáticas como el oso polar, la arará en Brasil y el almiquí en Cuba.

c) La polución ambiental que, por diversas causas (muchas inducidas como la obsolescencia programada), convierten en verdaderos reservorios de fealdad prados, ciudades y mares, especialmente, en países de la periferia.

d) La desertificación, entre otras causales, por la falta de agua: causa a su vez de hambrunas y crisis migratorias en países del cuerno africano. Según se presagia, la falta de agua constituirá la causa de futuras guerras: amenaza que ya se cierne sobre la región de la Amazonia.

e) Las guerras desatadas por razones geopolíticas, étnico-religiosas o simplemente de rapiña, que asolan al Medio Oriente y a África, y tienen repercusiones terroristas en las propias Metrópolis que las incitan.

f) La robotización, matematización y digitalización de los procesos mentales, facilitados por el desarrollo de las TIC y su empleo cada día más generalizado en los diversos ámbitos de la actividad humana. Cada día se acercarán más, casi hasta confundirse, los dominios de la ciencia ficción y la realidad; el androide, el hombre biótico y el ser humano.

Estas y muchas otras expresiones de la crisis socioambiental, que aquejan a la sociedad globalizada de hoy, son engendradas por una multiplicidad de factores 
objetivos y subjetivos atribuibles a la falta de cuidado, egoísmo, soberbia, ignorancia o estulticia de la única especie inteligente que ha demostrado ser capaz de autoextinguirse. La especie humana, aunque con diferentes cuotas de responsabilidad, ha ido erosionando el patrimonio estético natural. Lo cual, al decir de Marx, propició el desarrollo de los sentidos estéticos ${ }^{8}$. Con ello también fue posible, el desarrollo de la capacidad de expresarse y percibir de acuerdo a las leyes de la belleza (condicionadas por el ideal de perfección genérica de cada objeto o fenómeno), en cualesquiera de la actividad práctico-espiritual: incluyendo la práctica artística. En las condiciones del Paleolítico Superior, con una función mágica pero significativamente estética, el Homo sapiens ya fue capaz de cifrar su huella estética en los palimpsestos de trazos realistas, en las cavernas de Altamira y Lescaux. Cuando eso, por supuesto, no había sufrido todavía el proceso de extrañamiento o enajenación, que habría de cercenar dicha capacidad de expresión y percepción integral del mundo, al perder su propia integralidad con la atomización y polarización de la conciencia (la separación dicotómica y metafísica entre la mente racional y la mente emocional): tan criticada por Edgar Morin y otros paladines de la complejidad.

Eso aconteció más tarde con la especialización de la actividad, es decir, al perder su carácter integral. Primeramente, con la diferenciación entre agricultores y pastores, y posteriormente, con la aparición de la artesanía y la incipiente propiedad privada que dio lugar a la división de la sociedad en clases sociales. El nacimiento de sacerdotes, guerreros, militares, filósofos y artesanos condujo, a la vez, a la especialización de la conciencia y a la pérdida de la capacidad de objetivación y, en correspondencia, subjetivización de la naturaleza no humana. Y en la perspectiva del desarrollo filogenético y ontogénico ${ }^{9}$ (de la especie humana), la pérdida o deterioro de la condición

\footnotetext{
${ }^{8} \mathrm{~A}$ los "sentidos estéticos" Marx los denominó "sentidos humanos".

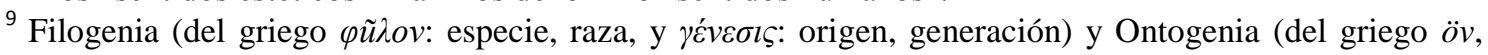

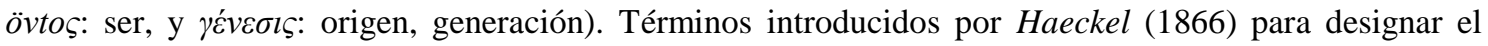
desarrollo histórico, genérico (filogenia) e individual (ontogenia) de los organismos. En el proceso evolutivo de la naturaleza viva, la filogenia y la ontogenia se hallan indisolublemente ligadas, se condicionan recíprocamente. En la Ley biogenética: la ontogenia es el resultado del desarrollo histórico, es decir, es un resultado de la filogenia; por otra parte, la filogenia se forma sobre la base de los cambios individuales, es decir, sobre la base de la ontogenia. En esta interacción se refleja la unidad de la parte (en el individuo) con el todo (el género), de lo singular con lo general, la dialéctica del proceso, en forma de espiral, de desarrollo, en cada una de cuyas etapas se reproducen, en forma superada, los saltos cualitativos realizados en las etapas precedentes. Darwin expuso la idea de la unidad entre filogenia y ontogenia, idea que fue desarrollada, entre otros, por Haeckel y Michurin.
} 
estética percibida todavía con claridad por los pitagóricos, al desarrollar una cosmovisión en términos de sinfonía musical universal.

Como es conocido, y tan criticado por los filósofos de la Escuela de Frankfurt (Adorno, Horkheimer, Benjamin), la enfermedad de la razón o del extrañamiento se agudizó con la irrupción de la Modernidad: a partir de la cual se ha convertido, virtualmente, en una pandemia espiritual que amenaza la sustentabilidad estética ${ }^{10}$ de la condición humana, en virtud de las consecuencias de la crisis socioambiental que deterioran las condiciones (materiales y espirituales) de la convivencia estética entre los seres humanos, globalizando la fealdad.

En esas condiciones, será necesaria la (re) semantización de conceptos, a fin de asumir los contenidos (estéticamente significativos) emergentes de la realidad virtual, lo cual tendrá un insospechado impacto sobre la condición humana: toda vez que, a partir de ahora, no responderá más a la dinámica del desarrollo histórico-natural de la especie humana, sino a una legalidad nueva, cuyas características se irán revelando solo con su devenir filogenético. Algo que rebasa, en el presente, nuestras expectativas cognoscitivas.

\section{El cambio de mentalidades: la Educación Estético-Ambiental}

La necesidad de un cambio de mentalidad para enfrentar las consecuencias del cambio climático ha sido proclamada por Irina Bokova, Directora General de la Unesco, a raíz de la convocatoria de la vigésimo primera Conferencia de las Partes de la Convención Marco de las Naciones Unidas sobre el Cambio Climático 2015 (COP21), cuando dijo:

La visión de la Unesco es clara: hemos de cambiar las mentalidades y no el clima, utilizando la educación, la cooperación científica, el pensamiento crítico y el debate que son posibles gracias a la libertad de expresión y de información, algo que promoveremos en el mundo. $(2015$, p. 5)

\footnotetext{
${ }^{10}$ Denomino sustentabilidade estética à escala ou espectro valorativo que se corresponde, em termos gerais, com o ideal social da perfeição genérica (indicador da qualidade estética) dos objetos e fenômenos da realidade objetiva. Por esse motivo, deve ser assumida como medida da dimensão qualitativa do desenvolvimento econômico e social, e humano em geral, com o objetivo de avaliar o impacto (positivo ou negativo) sobre os objetos e fenômenos que, do ponto de vista estético, são por ele afetados e que afetam ao próprio homem, já que a degradação das condições estéticas do meio ambiente corrói a consciência estética (individual e social) e, portanto, empobrece a atividade orientadora valorativa, e especificamente estética, do indivíduo no mundo circundante. (Ver ESTÉVEZ, P. R. A alternativa estética na educação. Rio Grande: Editora da FURG, 2009. p. 60).
} 
Ahora bien, un cambio de mentalidades implica un cambio de ética "a partir del calentamiento global" que no reside en la razón por cuanto, según aduce Leonardo Boff:

La razón -y esto la misma filosofía lo reconoce- no es ni el primero ni el último momento de la existencia. Por eso no explica todo. Se abre hacia abajo, de donde surge algo más elemental y ancestral, la afectividad y el sentimiento profundo. Irrumpe hacia arriba, hacia el espíritu, que es el momento en que la conciencia se siente parte de un todo y que culmina en la contemplación y en la espiritualidad. Por lo tanto, la experiencia de base no es el "pienso, luego existo", sino "siento, luego existo". En la raíz de todo no está la razón ("logos") sino la pasión ("pathos"), que se expresa por la sensibilidad y por el afecto. (BOFF, 2013, p.9)

Ya a fines del siglo pasado, un renombrado esteta de la naturaleza, Iván Smolianinov, había alertado en torno a la necesidad de educar la visión estéticoecológica del mundo, erosionada por la crisis de valores: con un indudable impacto en la crisis de la escuela revelada por el Informe Faure, de la Unesco, a principios de la década de los años 70. Según Smolianinov,

[...] la vida obliga hoy a educar en todas las personas, desde la infancia, una visión estético-ecológica del mundo [...] enseñar a comprender la ecología de la belleza y recrearse con la belleza de los ecosistemas; restablecer el gusto hacia la naturaleza, embotado o muerto por la urbanización; corregir, resueltamente, el estilo de nuestra existencia sin "naturaleza", que le quita al hombre la satisfacción por la vida". (1984, p.141)

Precisamente, en función de enseñar a comprender la ecología de la belleza y recrearse con la belleza de los ecosistemas, hemos insistido en la necesidad de socializar la Educación Estético-Ambiental, como una modalidad de la educación en valores con una orientación transdisciplinar y transartística, orientada a preservar (y en muchos casos, rescatar) la condición estética del ser humano. O dicho de otra manera, la sustentabilidad estética de la condición humana: que por su importante papel en el proceso de hominización de nuestros ancestros, hemos enarbolado como un principio del desarrollo humano y social.

En A alternativa estética na educação, se definió la sustentabilidad estética en los siguientes términos:

Denomino sustentabilidade estética à escala ou espectro valorativo que se corresponde, em termos gerais, com o ideal social de perfeição genérica (indicador da qualidade estética) dos objetos e fenômenos da realidade 
objetiva. Por esse motivo, deve ser assumida como medida da dimensão qualitativa do desenvolvimento econômico e social, e humano em geral, com o objetivo de avaliar o impacto que, do ponto de vista estético, são por ele afetados e que afetam ao próprio homem, já que a degradação das condições estéticas do meio ambiente corrói a consciência estética (individual e social) e, portanto, empobrece a atividade orientadora valorativa, e especificamente estética, do indivíduo no mundo circundante. (ESTÉVEZ, 2009, p. 60)

Asimismo, en el capítulo "A orientação estética na educação ambiental: a sustentabilidade estética", del mismo libro, se hizo explícita la necesidad de desarrollar una conciencia ambiental inclusiva, que promueva la preservación de la naturaleza (humana y no humana) y de sus atributos estéticos. Así lo resumió Estévez:

Em síntese, falamos da necessidade de inserir o conceito sustentabilidade estética como um referente essencial da teoria e da prática da Educação Ambiental, no entendimento de que não pode haver um processo de preservação da natureza sem que se estabeleça e consolide um modo de vida, e por extensão, um estilo de vida esteticamente sustentável: que pressupõe a sustentabilidade estética do desenvolvimento socioeconômico e humano em geral. Portanto, todo desenvolvimento será insustentável se não considerar como uma condição necessária a própria sustentabilidade estética, algo até agora preterido pela racionalidade instrumental operante na lógica cartesiana inerente à cultura ocidental. (2009, p. 60-61)

Como puede constatarse, este concepto asumió (como parte de su corpus teórico) la reflexión sobre la génesis del valor estético que Estévez comparte con Yuri Boriev:

La significación social de los objetos, su importancia para la vida de las personas y su capacidad para ser objetos de asimilación conforman la base de su valor estético. La «realidad», la materialidad, la integridad del mundo, la precisión y la sensibilidad concreta de sus objetos son la base natural innata de sus propiedades estéticas. Gracias a la producción social, los fenómenos del mundo actúan y participan en la esfera de los intereses del hombre y encuentran importancia para la humanidad. (BORIEV, 1969, p. 8) ${ }^{11}$

${ }^{11}$ En el capítulo "El saber sensible en la educación" (p.65-72), del libro Educar para el bien y la belleza, se hizo énfasis en la ascendencia natural y social de los valores estéticos como expresión de la objetivación del homo sapiens en la naturaleza no humana y la consiguiente subjetivización de esta en el azaroso proceso de su hominización. 
Al ampliarse el alcance de la sustentabilidad estética hasta abarcar el variado espectro del desarrollo humano ${ }^{12}$, se rebasaron los habituales límites epistemológicos de lo estético, ceñido al dominio del arte y la literatura, con menosprecio de las esferas de la naturaleza y del trabajo. Para ello, se retomó el vocablo griego Aisthesis que, por una parte, tributa a la formación de una cultura de los sentimientos (en la acepción de la estesia), y por otra, al desarrollo de la sensibilidad (en la acepción de la estética). Ambas acepciones tributan al desarrollo integral de la conciencia, que extrapola las expectativas disciplinarias en el trabajo educativo (rebasando, por tanto, las perspectivas meramente estética y ambiental). De esta forma, la acción educativa opera como un metafactor que modela la conciencia: concebida en la unidad indisoluble de conocimientos, saberes y valores, que se potencian en la interacción mutua y que generan una nueva calidad (inducida en un proceso educativo con una orientación transdisciplinar).

La conveniencia de introducir la sustentabilidad estética como un concepto rector en la EA, respondió a la necesidad de revertir el proceso de desestetización o pérdida de la condición estética de la especie humana, tanto en la perspectiva ontogénica como filogenética de su desarrollo histórico-natural. En dicho proceso, como puede intuirse, actuaron tres factores fundamentales: la especialización de la actividad humana, la pérdida del patrimonio estético natural, y por consiguiente, del individual y social, y la racionalidad instrumental.

En este sentido, la especialización de la conciencia explica la disyunción entre la mente racional y la mente emocional (GOLEMAN, 2001), y finalmente, el imperio de la razón sobre la emoción. Enfatizando la idea de la supremacía de la razón sobre la emoción en la época actual, Humberto Maturana consignó:

\footnotetext{
Vivimos una cultura que ha desvalorizado a las emociones en función de una supervaloración de la razón, en un deseo de decir que nosotros, los humanos, nos diferenciamos de los otros animales en que somos seres racionales. Pero resulta que somos mamíferos, y como tales, somos animales que viven en la emoción. (1991, p. 88)
}

\footnotetext{
${ }^{12}$ El dominio de la sustentabilidad estética ha estado restringido, en las pocas alusiones que pueden encontrarse en la teoría de la EA, a los atributos y cualidades (de índole estética) de la naturaleza no humana, a determinados materiales de uso en la construcción de inmuebles y a la cosmética.
} 
Debemos considerar que para este autor las emociones "son dinámicas corporales que especifican los dominios de acción en que nos movemos [...] Nada nos ocurre, nada hacemos que no esté definido como una acción de una cierta clase por una emoción que la hace posible”. (MATURANA, 1991, p. 88-89)

Precisamente, la enfermedad de la razón (que se extiende por el mundo con visos de pandemia) reclama la presencia de las emociones y una terapia radical en términos de repoblación axiológica de la conciencia, en aras del rescate de la condición humana, cuya sustentabilidad estética se torna cada vez más vulnerable. A ese rescate, precisamente, ha de contribuir la Educación Estético-Ambiental (EEA), como modalidad de la educación en valores, en las condiciones de la escuela contemporánea. En general, tratándose de una modalidad educativa relativamente joven, la EEA es susceptible de nuevos aportes y desarrollos

Con ese interés, analizamos los sentidos y significados (representaciones) que un grupo de Instructores (as) de Arte de Manicaragua (Villa Clara) y un grupo de académicos (AS) de Artes Visuais - Licenciatura, de la Universidade Federal do Rio Grande - FURG (Brasil) atribuyeron a la Educación Estético-Ambiental y su papel para una formación más integral de la personalidad. Para ello, nos apoyamos en dinámicas de sensibilización estético-ambiental, que fungieron como potentes herramientas para el desarrollo de una educación de y para lo sensible, a través de la realización de los cursos de extensión intitulados: “A dimensão estético-ambiental na ambientalização curricular dos (as) educadores (as) em Arte" (Brasil) y "Seminario-Taller de Sensibilización Estético-Ambiental" (Cuba). En el caso de Brasil, las experiencias fueron realizadas de abril a septiembre del 2015; y en el caso de Cuba, del 4 al 15 de enero de 2016. Esta pesquisa tuvo un carácter cualitativo y se fundamentó en la perspectiva hermenéuticadialéctica de Minayo.

La fuente de las informaciones primarias las obtuvimos, principalmente, de la revisión bibliográfica exhaustiva, especialmente de libros, artículos, documentales, ensayos y conferencias relativas al objeto de estudio; mientras que las secundarias las obtuvimos de los cuestionarios semi-estructurados aplicados (con la autorización de los sujetos colaboradores) y de la relectura y análisis de las narrativas, resultantes de las actividades implementadas en los talleres (las oficinas) de sensibilización estéticoambiental. Para la organización, el análisis y la interpretación de las informaciones nos 
afiliamos al Método de Interpretación de Sentidos de Minayo, con un carácter hermenéutico-dialéctico, correspondiente a las concepciones sociofilosóficas de nuestros principales referentes.

Destacamos, además, nuestro interés por constatar si estas prácticas docenteartísticas podían ser transculturales, o sea, aplicadas en diferentes contextos, sin que las diferencias culturales mellaran la significación y la trascendencia de las mismas para los sujetos colaboradores, el ámbito educativo y la sociedad en su conjunto.

\section{REPRESENTACIONES DE LOS (AS) ACADÉMICOS (AS) EM ARTES VISUALES - LICENCIATURA DE LA FURG Y LOS (AS) INSTRUCTORES (AS) DE ARTE DE MANICARAGUA}

Al analizar las diferencias entre las narrativas de los (as) académicos (as) em Artes Visuales - Licenciatura y las de los (as) Instructores (as) de Arte, se hizo evidente un desbalance (a favor de los primeros) en el predominio de categorías con una significación emocional, en tanto, en los segundos, predominaron las categorías con una orientación racionalista.

Esa singularidad, en el caso de los (as) instructores (as) de Arte, pudiera explicarse por el impacto anestesiante sobre la personalidad que trajo consigo la denominada crisis de valores, producida en Cuba tras el derrumbe de la Unión Soviética y del Campo Socialista, y cuyo impacto (tanto en la mente emocional como en la mente racional) aún perdura en las presentes generaciones: poniendo de relieve la pertinencia, (como se puso de manifiesto en las narrativas de los (as) propios (as) instructores (as) de Arte), de prácticas de sensibilización orientadas al rescate de la sensibilidad y a la concientización de los (as) educadores (as).

En cuanto a las representaciones acotadas en los cuestionarios y las evaluaciones finales (tanto las de los (as) académicos (as) em Artes Visuales - Licenciatura de la FURG como las de los (as) Instructores (as) de Arte de Manicaragua), con una ostensible similitud, a pesar de las lógicas singularidades culturales; evidenciaron una clara comprensión acerca de la inobjetable importancia de la Educación Estético-Ambiental como una vía idónea para desarrollar procesos docente-educativos, orientados hacia una formación más integral de educadores (as) que, según Marx, deben ser educados previamente. Ello puede explicarse en función del conocimiento empírico (propio del buen sentido de los sujetos colaboradores, 
poseedores de ciertos conocimientos y saberes sobre la materia), y en función de los nuevos conocimientos y saberes adquiridos en los talleres de sensibilización, estructurados a partir de una información previa que consideró aspectos de carácter emocional y racional: lo que tributa a una concepción unitaria (integral) de la conciencia.

Asimismo, dichas representaciones revelaron la pertinencia de la orientación estético-ambiental de la educación en las condiciones de la crisis socioambiental contemporánea y, en especial, la necesidad de la ambientación curricular en el Curso de Artes Visuales - Licenciatura de la FURG y en la Licenciatura de Instructores (as) de Arte (actualmente sustituida en Cuba por la Licenciatura en Educación Artística) ${ }^{13}$ Habida cuenta de que sin una formación estético-ambiental, que comporte el desarrollo de la condición estésica y estética del ser humano, no puede lograrse una formación más integral, ni puede prepararse a los educadores que necesita la escuela del futuro. Y esa comprensión se percibió, nítidamente, en las exposiciones de ambos grupos de educadores (as), con una ostensible significación transcultural: comprensible en el marco de la globalización de las ideas y las políticas (sobre todo, en las esferas de la educación y la cultura): aunque, infelizmente, con visos neoliberales.

En general, el análisis e interpretación de las representaciones de ambos grupos de sujetos colaboradores permitieron hacer las siguientes inferencias:

a) El papel relevante de la EEA para una formación más integral de educadores (as) en arte, ya que su perfil profesional tiene una proyección holística (que engloba la tríada enseñanza - pesquisa - extensión) y una orientación humanista que es consustancial, por naturaleza, a toda modalidad de la educación en valores.

b) La pertinencia de la educación emocional, sobre todo en las condiciones de la crisis socioambiental contemporánea, como un factor sustentador de la condición humana afectada por la enfermedad de la razón: que reproduce el capital en el contexto de la globalización de las políticas neoliberales y que hacen del ser humano un mero robot consumidor.

\footnotetext{
${ }^{13}$ Por cierto, el actual Programa de Estética de esta Licenciatura (Teoría y Práctica de la Educación Estética), confeccionado por Estévez y basado en sus propias concepciones) se acogió, íntegramente, a esta orientación.
} 
c) La necesidad de la ambientación curricular de los cursos de formación de educadores (as), especialmente en arte, con la inserción orgánica de contenidos de la EEA en el Curso de Artes Visuales - Licenciatura y en la Licenciatura en Educación Artística, rebasando el carácter racionalista reductor que los caracteriza hoy día.

d) La innegable aproximación de dichas representaciones a la orientación estético-crítica de las concepciones pedagógicas de Paulo Freire, toda vez que concibe la educación liberadora y transformadora como una síntesis que engloba, en una unidad indisoluble, lo racional y lo sensible, lo ético y lo estético, como concreción de su visión dialéctica del mundo y de la condición humana: lo cual hace de su obra una referencia obligada, como valioso antecedente, de la EEA.

Los resultados obtenidos, sumamente positivos, aparecieron previamente como intuiciones en las obras de Pablo René. De hecho, el Proyecto "Educar para el bien y la belleza" ${ }^{14}$ se fundamentó en estos presupuestos, que ahora recibieron una sustentación científica a través de los talleres de sensibilización estético-ambiental.

Ello representa, indudablemente, un importante paso en el propósito de lograr procedimientos capaces de cultivar las potencialidades estético-culturales de los seres humanos; de preservar la condición estética de nuestra especie, y en última instancia, su propia sustentabilidad estética en un mundo cada vez más hostil y anestésico. Y sobre todo, un paso trascendente para aspirar a una formación más integral de educadores y educadoras: ya que no será posible alcanzarlo sin una educación que tribute tanto al desarrollo de la mente como al cultivo del corazón. En fin, una educación liberadora y transformadora, por el hombre y para el hombre, tal como la concibió Paulo Freire.

\section{CONSIDERACIONES FINALES}

La crisis socioambiental contemporánea, de carácter global, se agrava cada día más en virtud de la globalización de las políticas neoliberales al servicio del capital transnacional. Debido a eso, no es posible convertir en realidad la aspiración de McLaughlin: hacer que el gusano del industrialismo se convierta en una mariposa (1997, p. 256). Sencillamente, porque la glorificación de la industria, como ideal supremo de la civilización, presupone la destrucción de la biodiversidad, y como

\footnotetext{
${ }^{14}$ Los profesores Pablo René Estévez y Lurima Estevez Alvarez forman parte de este proyecto.
} 
consecuencia, la probable desaparición de la propia especie del Homo sapiens. En ese mundo saturado de agrotóxicos (plaguicidas, fungicidas, herbicidas) quedan pocas posibilidades de supervivencia para la mariposa y para el sentimiento de lo bello, como una de las conquistas esenciales de la condición humana.

El proceso de instrumentalización de la razón, que emergió con la Modenidad como lógica consecuencia del proceso de enajenación de los seres humanos, indujo la pérdida de los valores estéticos de la naturaleza, y como un reflejo de ello, la desestetización de la vida personal y social. Esta situación, por supuesto, condicionó el desafío de los educadores y las educadoras de hoy, responsabilizados con ofrecer una formación más integral, que capacite a los discentes para cumplir con las elevadas exigencias de la producción contemporánea, a la vez que garantice una educación de calidad (especialmente, en los aspectos emocionales del proceso de enseñanzaaprendizaje), y los haga más sensibles y humanos en la comprensión de la realidad circundante y en las relaciones con el mundo natural y social.

En estas condiciones, es obvio, no puede salvarse ni la educación como alternativa para recuperar el equilibrio entre los aspectos emocionales (estéticos por naturaleza) y los racionales, de una conciencia cada vez más desintegrada, según lo planteado por Edgar Morin, a partir de la perspectiva del pensamiento complejo.

Es ahí, precisamente, donde cobran relevancia las prácticas de sensibilización como herramientas para el desarrollo estético-ambiental de educadores (as). Lo que se pudo constatar a través de las exposiciones de los (as) académicos (as) em Artes Visuales - Licenciatura de la FURG (Brasil, 2015) y los instructores de Arte de Manicaragua (Cuba, 2016). ${ }^{15}$ En estos (as) talleres (oficinas) se demostró la pertinencia y la viabilidad de los procedimientos estético-educativos para despertar la conciencia crítico-estética e inducir representaciones (estéticamente significativas), en particular, en educadores y educadoras en arte: promoviendo una formación más integral a partir del desarrollo estético de la personalidad.

Por otra parte, dichas representaciones fueron sumamente elocuentes respecto a la necesidad de la ambientación curricular del Curso de Artes Visuales - Licenciatura y

\footnotetext{
${ }^{15}$ Ver ESTEVEZ ALVAREZ, L. La Educación Estético-Ambiental en la formación de educadores (as). Tesis. (Doutorado em Educação Ambiental) - Programa de Pós-Graduação em Educação Ambiental (PPGEA), Universidade Federal do Rio Grande (FURG, Rio Grande, RS), 2017. El autor, co-orientador de la Tesis de Lurima, participó como organizador y observador en los talleres de Cuba.
} 
la Licenciatura en Instructores de Arte de las universidades cubanas, en virtud de las carencias de conocimientos y saberes estético-ambientales en los currículos respectivos. Amén de lo anterior, según las informaciones recogidas en la investigación (siguiendo el método hermenéutico-dialéctico de Maria Cecília de Souza Minayo ${ }^{16}$ ), los referidos talleres (las oficinas) posibilitaron el despertar de la mente emocional, tributando, a partir de una perspectiva estético-ambiental, a una formación más integral de los participantes. Todo lo cual reveló la importancia de la Educación Estético-Ambiental, como modalidad emergente de la educación en valores, para enfrentar el impacto antiestético de la crisis socio-ambiental global en la sociedad contemporánea.

\section{REFERENCIAS}

ARTHUS-BERTRAND, Y. Documental Home. Producción Denis Carot y Luc Besson. Coproducción ELZÉVIR FILMS-Europacorp, 2009. Disponible en: http://www.youtube.com/watch?v=SNRHxh6XepM. Consultado: 10/02/2016.

ESTÉVEZ, P. R. La sustentabilidad estética en el desarrollo humano. In: ESTÉVEZ, P.R. (Org.). A Educação Ambiental em perspectiva estética. Rio Grande, RS, Brasil: Editora da FURG, 2011.

BOFF, L. Ética a partir del calentamiento global, 3 junio 2013. Disponible en: www. elciudadano.cl/columnas/ética-a-partir-del-calentamiento-global/06/03/. Consultado: $12 / 08 / 2017$.

BOKOVA, I. Cuba: París abre nueva etapa para enfrentar el cambio climático. Periódico Granma, La Habana, Año 51, nº . 298, p. 5, diciembre 2015.

BORIEV, Y. Estética. Moscú: Progreso, 1969.

CARRASCO MARTIN, J. Los diez grandes de la industria de la muerte. El dinero ensangrentado. Periódico Juventud Rebelde, La Habana, Año 51, n ${ }^{0}$. 220, p. 6, julio 2016.

CASTRO, F. La marcha hacia el abismo. La Habana, Cuba, 5 de enero 2012. Disponible en: www.cubadebate.cu/reflexiones-fidel/2012//01/05/la-marcha-hacia-elabismo/\#.WdT8T1vW24Y. Consultado: 12/03/2017.

\footnotetext{
${ }^{16}$ Ver GOMES, R. Análise e interpretação de dados de pesquisa qualitativa. In: FERREIRA DESLANDES, S.; GOMES, R.; MINAYO, M.C de Souza (Org.) Pesquisa Social. Teoria, método e criatividade. 28. ed. Petrópolis, Rio de Janeiro: Editora Vozes, p. 79 - 108. 2009.
} 
ESTÉVEZ, P.R. A alternativa estética na educação. Rio Grande: Editora da FURG, 2009.

ESTEVEZ ALVAREZ, L. La Educación Estético-Ambiental en la formación de educadores (as), 2017. Tesis. (Doutorado em Educação Ambiental) Instituto de Educação, Programa de Pós-graduação em Educação Ambiental (PPGEA), Universidade Federal do Rio Grande (FURG), Rio Grande, RS, Brasil, 2017.

FAURE, E. et. al. Aprender a ser. Madrid: Editorial Alianza, 1973.

GOLEMAN, D. Inteligência emocional: a teoria revolucionaria que redefine o que é ser inteligente. Rio de Janeiro: Objetiva, 2001.

GOMES, R. Análise e interpretação de dados de pesquisa qualitativa. In: FERREIRA DESLANDES, S.; GOMES, R.; MINAYO, M.C. de Souza (org.) Pesquisa Social. teoria, método e criatividade. 28. ed. Petrópolis, Rio de Janeiro: Editora Vozes, p. 79 $-108.2009$.

GÓMEZ FIGUEREDO, E.J. La tierra podrá calentarse hasta 4,9 grados. Periódico Granma, La Habana, Año 53, nº . 182, p. 6, agosto 2017.

GODOY, E. Los biocombustibles se roban la comida. Pequeños Estados insulares unen fuerzas rumbo a Río+20. Periódico Granma, La Habana, p. 8, mayo 2012.

HORKHEIMER, M. Crítica de la Razón Instrumental. Buenos Aires: El Ateneo, 1973.

IONESCO, D; TRAORE CHAZALNOËL, M. Contribución de la OIM en "El año del clima" - París 2015. $21^{\text {a }}$ Conferencia de las Partes en la Convención Marco de las Naciones Unidas sobre Cambio Climático. Disponible en: https://publications.iom.int/system/files/pdf/mecc-cop-21-sp-web-12nov2015.pdf. Consultado: 10/06/2016.

MCLAUGHLiN, A. El corazón de la ecología profunda. Revista Cuba Verde. En busca de un modelo para la sustentabilidad en el siglo XXI. La Habana: Editorial José Martí, 1997.

MARX, C. Obras Escogidas. Moscú: Progreso, 1965. 
MORIN, E. A cabeça bem-feita: repensar a reforma, reformar o pensamento. 5. ed. Rio de Janeiro: Bertrand Brasil, 2001.

PELÁEZ, O. La amenaza de la desertificación. Periódico Granma, La Habana, Año $52, \mathrm{n}^{0} .55$, p. 8 , marzo 2016.

RAMONET, I. El mundo en el 2030. Periódico Le Monde Diplomatique, mayo 2013. Disponible en: https://www.rebelion.org/noticias/2013/5/167645.pdf. Consultado: 27/09/2017. (También puede consultarse en el site: http://www.mondediplomatique.es/?url=editorial/0000856412872168186811102294251000/editorial/?arti culo=e81107d95-88cd-46a5-a22e-d69e48ef3c63)

RICHARDS, P. Pequeños Estados insulares unen fuerzas rumbo a Río+20. Periódico Granma, p. 8, mayo de 2012.

SMOLIANINOV, I. La naturaleza en el sistema de la educación estética. Moscú: Editorial Prosvieshenie, 1984. 